\title{
Bridging the digital divide in older adults: a study from an initiative to inform older adults about new technologies
}

Ya-Huei $\mathrm{Wu}^{1,2}$

Souad Damnée ${ }^{1,2}$

Hélène Kerhervé ${ }^{1,2}$

Caitlin Ware ${ }^{1,3}$

Anne-Sophie Rigaud ${ }^{1,2}$

'Department of Clinical Gerontology, Broca Hospital, Assistance PubliqueHôpitaux de Paris, ${ }^{2}$ Research

Team 4468, Paris Descartes

University, ${ }^{3}$ Centre de Recherche en Psychanalyse, Médicine et la Société,

Paris Diderot University, Paris, France
This article was published in the following Dove Press journal:

Clinical Interventions in Aging

9 January 2015

Number of times this article has been viewed
Correspondence: Ya-Huei Wu Hôpital Broca, 54-56, rue Pascal, 750I3

Paris, France

Tel +33 | 44083507

Fax +33 | 44083510

Email yahuei.wu@brc.aphp.fr
Purpose: In a society where technology progresses at an exponential rate, older adults are often unaware of the existence of different kinds of information and communication technologies (ICTs). To bridge the gap, we launched a 2-year project, during which we conducted focus groups (FGs) with demonstrations of ICTs, allowing older adults to try them out and to share their opinions. This study aimed at investigating how participants perceived this kind of initiative and how they reacted to different kinds of ICTs.

Patients and methods: In total, 14 FGs were conducted with community-dwelling older adults, with a frequency of two FGs on the same topic once per trimester. Twenty-three older adults (four men and 19 women) attended at least one FG but only nearly half of them were regular attendants (ten participating in at least five sessions). Age of participants ranged from 63 years to 88 years, with a mean of 77.1 years. All of them had completed secondary education. The analyses of the data were performed according to inductive thematic analysis.

Results: Four overarching themes emerged from the analysis. The first concerned participants' motivation for and assessment of the project. The second theme identified the underlying factors of the "digital divide" between the younger and the older generations. The third theme concerned the factors of technology adoption among older adults. The fourth one identified participants' attitudes toward assistive ICTs, designed specifically for older adults ("gerontechnologies").

Discussions and conclusion: This project encouraging older adults to be informed about different kinds of ICTs was positively rated. With regard to ICTs, participants perceived a digital divide. The underlying factors are generation/cohort effects, cognitive and physical decline related to aging, and negative attitudes toward technologies. However, more and more older adults adopt different kinds of ICTs in order to fit in with the society. Concerning assistive ICTs, they manifested a lack of perceived need and usefulness. Also, there was a negative image of end users of this kind of technologies. The so-called gerontechnologies specifically targeting older adults contain stigmatizing symbolism that might prevent them from adopting them.

Keywords: assistive technologies, attitude, digital divide, gerontechnology, technology adoption, technology acceptance

\section{Introduction}

Gerontechnology is defined as "the study of technology and aging for ensuring good health, full social participation, and independent living through the entire life span."1 Gerontechnology is interdisciplinary in nature, combining gerontology (eg, medical, psychological, and social sciences of aging) and technology (eg, robotics, ergonomics, information and communication technologies [ICTs]). In this perspective, older adults are studied from the lens of living among a dynamic technological society, while technology is studied from the viewpoint of its potential to improve their daily living and to facilitate 
their social participation. ${ }^{2}$ In Europe, in the face of aging societies, it is considered that technological innovation can enhance the quality of life for older adults and people with disabilities, while in the meantime, it creates new economic and business opportunities. ${ }^{3}$ In the same vein, in France in 2013, the Minister of Industry and Growth, and the Junior Minister for the Elderly and Independence jointly launched a sector called "Silver Economy", aiming at the creation of personalized services and technologies for maintaining autonomy in older people.

We can distinguish two categories of technologies when describing technology use in older adults. One concerns new ICTs that target a broader market population. The other concerns assistive technologies (ATs) targeting people with special needs, such as hearing loss, memory loss, mobility difficulties, and wandering. Due to age-related cognitive, sensorial, and physical declines and health issues, there is a potential need for ATs in older adults to help them remain independent as long as possible. ${ }^{4,5}$ In response to this potential demand, ICT-related products, such as robotics, smart home technology, assistive communication devices, and sensors for social alarms, are either under research and development or already on the market (http://www.silvereco.fr/). These products are commonly referred to as gerontechnologies.

Older adults frequently use long-standing technologies, while they are slower at adopting new ones. ${ }^{6,7}$ It has been well established that compared with younger people, older adults have lower access to and usage of recent technologies. For example, a recent French national survey showed that among older adults born before 1930 , only $8.4 \%$ of them use the Internet, while Internet user rate rises to $32.9 \%$ among people born between 1930 and 1949 and to almost 100\% among those born after $1990 .{ }^{8}$ In spite of the promising and distinct advantages that can be provided by technologies, many older adults do not seem ready to embrace them. ${ }^{9}$

In the theory of "diffusion of innovations", Rogers classifies individuals within a social system on the basis of innovativeness, and older adults fall within the category of "laggard". ${ }^{10}$ Individuals in this category are described as more conservative, traditional, skeptical, suspicious, cautious, and risk averse when they encounter innovations. They would only adopt an innovation after observing that it has been successfully adopted by other members of the social system and that they see clear benefits for themselves. Thus, acceptance and adoption of ICT-related ATs in older adults is a very challenging issue considering the characteristics of this population in relation to technology. To encourage technology adoption, from the perspective of Rogers' "diffusion of innovations" theory, designers should carefully take into account the "perceived attributes" of an innovation. ${ }^{11}$ A product or a device must be compatible with an older adult's lifestyle and values, fit in with his/her needs, and be easily assimilated into his/her life (compatibility). It must be easy to understand and to use (complexity). Its benefits must be evidenced; it must have a clear advantage over the previous or traditional product or system (relative advantage). It is also important to provide opportunities to try out a product (trialability) and observe others using a technology or receive their feedback (observability).

It is often reported that older adults often lack knowledge or are unaware of many existing ICTs and ICT-related ATs. ${ }^{11,12}$ Heinz et al suggested conducting focus groups (FGs) on new technologies by integrating product demonstrations. This approach allows testing out and experimenting with devices, so that older adults can gain more knowledge and formulate informed opinions about usability and usefulness of technologies. ${ }^{11}$

Along the same line, in 2012, we launched a 2-year project called "Gerontechnology and You", during which we conducted FGs presenting a variety of technologies to older adults. The aim of this project was to inform older adults of the existence of different kinds of ICT-related products and to investigate how they perceived this kind of initiative. Their attitudes and reactions toward technologies were also recorded. In this paper, we describe the design of the study and present major themes from reflections formulated by our participants.

\section{Materials and methods Overview of the project "Gerontechnology and You"}

To achieve the objectives of the project, during a 2-year period from the beginning of 2012 to the end of 2013, we conducted 14 FGs on ICT-related products with community-dwelling older adults, with a frequency of two FGs on the same topic once a trimester. All of the FGs were conducted by the same two moderators (psychologists). The first topic was the overview of a variety of ICT-related products, followed by the presentation of a cognitive prosthesis, a videoconferencing application prototype, assistive and companion robots, and tablet computers and video games. In the final two FGs, we presented study results to participants and emergent themes from FG discussions for validation. Participants could confirm the researcher's interpretation and provide additional insight. ${ }^{13}$ Each FG began with a presentation of a product, which was followed by product manipulation in small groups (2-3 participants per group) and ended with discussions among participants. Moderators encouraged participants to express their opinions about each product 
on the following issues: ease of use, usefulness, advantages, disadvantages, and their intention to use it. The characteristics of participants and a brief description of FGs on the same topic are presented in Table 1.

This study was approved by the Committee of Ethical Evaluation for Research in Health held jointly by Cochin Hospital and Paris Descartes University.

\section{Participants}

Participants were contacted from a panel of volunteers who had previously agreed to participate in research studies led at Broca hospital. In total, 23 older adults (four men and 19 women) attended at least one FG: four attended seven sessions, three attended six sessions, three attended five sessions, two attended 4 sessions, 1 attended three sessions, seven attended two sessions, and three attended only one session. The number of participants to a given FG was between four and nine. Age of participants ranged from 63 years to 88 years, with a mean of 77.1 years. All of them had completed secondary education.
All participants signed an informed consent for participating in the study.

\section{Analyses}

All FGs were videotaped and then transcribed. The analyses of the transcripts were then performed according to inductive thematic analysis. ${ }^{14}$ The data collected from all the FGs were transcribed and analyzed by YHW and SD conjointly. The initial ideas were noted down and discussed during the data transcription. The transcribed data were then read and reread several times, which allowed data immersion and familiarization. The coding phase of the data was then initiated. These codes identified underlying ideas from the data that the researcher considered pertinent to the aim of the study. We focused on identifying recurrent attitudes and reactions to all technologies presented throughout the sessions rather than to one specific technology. The third stage consisted in formulating themes by grouping together codes that reflected similar overarching ideas. Major themes and subthemes applied to the data were defined and labeled.

Table I Characteristics of participants and a brief description of FGs for each topic

\begin{tabular}{|c|c|c|}
\hline & Participants & FG description \\
\hline Theme I: Introduction & $\begin{array}{l}\mathrm{N}_{\mathrm{FGI}}=7, \mathrm{~N}_{\mathrm{FG} 2}=6 ; \mathrm{II} \text { women, } 2 \text { men; } \\
\text { age range: } 63-86(m=75 . \mathrm{l})\end{array}$ & $\begin{array}{l}\text { Presentation of the project and introduction of different } \\
\text { kinds of ICT-related products with powerpoint }\end{array}$ \\
\hline Theme 2: Cognitive prosthesis & $\begin{array}{l}\mathrm{N}_{\mathrm{FGI}}=5, \mathrm{~N}_{\mathrm{FG} 2}=8 ; \text { I I women, } 2 \text { men; } \\
\text { age range: } 63-86(m=77.2)\end{array}$ & $\begin{array}{l}\text { Presentation and demonstration of an event/appointment } \\
\text { reminder by a commercial agent of the company } \\
\text { commercializing the product } \\
\text { Testing and manipulation of the product in small groups }\end{array}$ \\
\hline Theme 3: Videoconferencing application & $\begin{array}{l}N_{F G 1}=6, N_{F G 2}=9 ; 12 \text { women, } 3 \text { men; } \\
\text { age range: } 63-86(m=77.6)\end{array}$ & $\begin{array}{l}\text { Presentation by two developers of a videoconferencing } \\
\text { application prototype securing communications from } \\
\text { privacy and intimacy violations } \\
\text { Testing and manipulation of the application prototype in } \\
\text { small groups }\end{array}$ \\
\hline Theme 4: Assistive and companion robots & $\begin{array}{l}N_{F G 1}=5, N_{F G 2}=6 ; 8 \text { women, } 3 \text { men; } \\
\text { age range: } 63-88(m=76.5)\end{array}$ & $\begin{array}{l}\text { Presentation by two psychologists of an assistive robot } \\
\text { (Kompai), a companion robot (Paro in two videos), and an } \\
\text { educational robot (Nao in a short video) } \\
\text { Testing and manipulation of Kompaï }\end{array}$ \\
\hline Theme 5: Tablet PC & $\begin{array}{l}N_{F G 1}=6, N_{F G 2}=8 ; 13 \text { women, I man; } \\
\text { age range: } 63-88(m=78.3)\end{array}$ & $\begin{array}{l}\text { Presentation by two moderators/psychologists of two } \\
\text { tablet PC: I) iPad and 2) a simplified tablet computer } \\
\text { (TOOTI-family) } \\
\text { Testing and manipulation of these two tablet computers } \\
\text { in small groups }\end{array}$ \\
\hline Theme 6: Video games & $\begin{array}{l}\mathrm{N}_{\mathrm{FGI}}=5, \mathrm{~N}_{\mathrm{FG} 2}=7 ; \text { I I women, I man; } \\
\text { age range: } 63-88(m=77.4)\end{array}$ & $\begin{array}{l}\text { Presentation by a researcher of different kinds of } \\
\text { video games with different interfaces: computer, tablet } \\
\text { computer, joystick, etc } \\
\text { Playing video games in small groups with I) Nintendo Wii, } \\
\text { 2) Kinect Xbox, and 3) tablet computers }\end{array}$ \\
\hline Theme 7: Review and conclusion & $\begin{array}{l}\mathrm{N}_{\mathrm{FGI}}=4, \mathrm{~N}_{\mathrm{FG} 2}=6 ; 9 \text { women, I man; } \\
\text { age range: } 63-88(m=79.6)\end{array}$ & $\begin{array}{l}\text { Presentation of results from analysis of FG discussions } \\
\text { Ask for participants to confirm the researcher's } \\
\text { interpretation and provide additional insight }\end{array}$ \\
\hline
\end{tabular}

Abbreviations: FG, focus group; ICT, information and communication technology; PC, personal computer. 
Finally, examples were chosen from the transcript to illustrate elements of themes in the "Results" section.

Major themes and subthemes were presented to participants for validation in the final two FGs. These themes were validated by most of the participants. By seeking the participants' views on the honesty and consistency of the research findings, we were able to judge the credibility of our findings. ${ }^{15}$

\section{Results}

Four major themes were identified: project participation, digital divide, ICT adoption, and opinions on assistive ICTs. A summary of these major themes and their subthemes is presented in Table 2.

\section{Project participation}

When asked the question "why did you take part in the project and what do you want to learn from this project?", most of the older adults initially mentioned that participating in this project would allow them to maintain an active engagement in life and society: they could meet and discuss with other people, make themselves useful by devoting time to research, and keep themselves up-to-date on technologies.

Participating in the group could contribute to aging well with the curiosity and the desire to move forward. It means that we are still interested in what happens in the world where we live and that we want to meet other people... Sometimes, it might be quite demanding to come here because I have

Table 2 Summary of major themes and subthemes of the data

\begin{tabular}{ll}
\hline Major themes & Subthemes \\
\hline Project participation & Active engagement \\
& Curiosity \\
& Solution finding for a proxy \\
& Anticipation for the future \\
& Empowerment \\
& Feelings of inferiority and obsolescence \\
Digital divide & Generation differences \\
& A lack of comfort, control, knowledge, and \\
& self-efficacy toward technology \\
& Age-related cognitive difficulties \\
& Technology anxiety \\
& Concerns about the risks of technology use \\
& Importance of training \\
& Compensating for difficulties \\
ICT adoption & Communicating with others \\
& Fitting in with society \\
& Social influence \\
Social pressure & No perceived needs for the moment \\
Potential future needs \\
ICTs
\end{tabular}

Abbreviation: ICT, information and communication technology. to take the subway to go very far (...) It makes up a part of my desire to be living. [P1, female, 83 years]

It gives me an impetus to keep up with what happens in the society. [P2, female, 88 years]

Two participants joined this project in order to find useful products for their proxies suffering from dementia. Another two participants mentioned that they would like to search for products to help them maintain their independence as long as possible.

I'm interested in the issues of aging, my future problems with aging and how to keep ourselves independent at home in spite of aging. [P3, male, 85 years]

At the final session, most of them found the FGs interesting and pleasurable. They discovered things that they had little knowledge about (eg, different kinds of technologies) and thought about what they would one day encounter with aging (eg, loss of autonomy and death). Talking about these issues helped them anticipate and be better prepared if one day they encountered these situations. They would know that some assistive products are available and would more easily accept these products to help them age well. Also, by giving their points of view about technologies for older people, some of them felt empowered.

The groups are enjoyable and give me some knowledge about what I might expect... with aging... I hope that I could age well. [P4, female, 63 years]

I hope that people who design new technologies will take into consideration what the elderly talk about instead of conceiving things that they find formidable... that in reality are not at all adapted to older people... this is an opportunity for us to express our opinions... I hope that it allows a mutual enrichment. [P5, female, 81 years]

\section{Digital divide}

In general, participants were fascinated by the potential of technologies, and for many of them, people who master technologies were considered to be empowered.

Me too, I admire this... I was on holiday at a friend's house. Her grandson had an I-phone. I was on the phone with my daughter and she told me that she had a disease that I didn't have any idea about. I pronounced the name and he took his I-phone and then gave me the definition. I was astonished... It happened 5 years ago... I was astonished to see a world where we could get instant responses. [P1, female, 83 years] 
However, throughout FGs, most of them reported that they lag behind the social trend, which moves with technology progress.

"I-PAD," this is a name that I have heard of but I don't understand what it is really... You talked about "Facebook"... These are words but I can't find any meaning to them. Precisely, I don't know what they mean... It's not that I don't want to go on the Internet but the train has left and I'm not on board. [P6, female, 82 years]

The differences between generations, concerning elements such as values, ways of thinking, and lifestyles, were considered to contribute to the digital divide.

...it's a different mentality from ours... our way of thinking is methodical, rational and rigorous (Cartesian)... the young have a digital mind. This is like two worlds confronting each other... we have to cope with it (two different worlds). [P1, female, 83 years]

To many of them, technology might cause anxiety due to a low level of comfort with and control of technology, age-related cognitive difficulties (eg, less attentive, psychomotor slowing), or a lack of familiarity. In addition, they frequently expressed wariness and concerns about the downsides and the risks of technology use, such as privacy violation, cybercrime, diminution of human contact, and dependence on technologies in younger generations. Risk aversion and a lack of technology efficacy could prevent them from using ICTs.

I heard it said at a TV show that people can get information about our bank account via the Internet. [P7, female, 72 years]

We've got to be very cautious with the Internet. [P5, female, 81 years]

We're right to be careful. [P8, female, 75 years]

Yes, even our ministers are spied on [P1, female, 83 years]

Are machines toxic? I think that in some way, they are for the following reasons. An organ which doesn't work weakens. When machines substitute not only for one's memory but also one's reasoning, one's (cognitive) functions atrophy. We lose our capacity to think, to make mental effort. Yet, we learn things through personal effort and reflection... [P3, male, 85 years]

Compared to the younger generations, some participants reported the feeling of being labeled as old fashioned and obsolete, due to a lack of knowledge on ICTs and their use, which could lead to a feeling of inferiority or powerlessness.

You can see this when you talk to your grandchildren. Me, when I ask for some explanations because I don't understand, they talk to me with breathtaking speed... I ask them to speak to me in good French... they made fun of me and said: "Granny, you had a brilliant career and look at what you have done in law courts..." [P5, female, 81 years]

For this group of seniors who did not acquire knowledge on the use of ICTs during their schooling and/or at work, tailored training was considered as the best way to bridge the gap of the digital divide.

I'd like to have a teacher who comes to my home and who explains to me with good vocabulary... once a month or a week... who can solve my problems. By doing this, I think that I could progress well. [P2, female, 88 years]

\section{ICT adoption}

Perceived needs for technology were often mentioned as a reason for its adoption. A few participants needed ICT products to help them compensate for cognitive difficulties (eg, referring to one's smart phone when encountering word-finding difficulties) or to be rescued in case of an emergency.

I fell down a number of times and I couldn't pick myself up. I told myself that I had to do something... now I pay 58 euros every month (for a remote alarm). [P10, female, 85 years]

Most of them mentioned the fact that they need technology to keep in touch with their relatives, to receive information, to communicate with others, and to be connected to the society. They frequently reported social pressure that pushes them to use technologies in order to fit in with the society. Otherwise, they would be excluded from it.

I was a member in an association but I never received anything from them. Someone (from the association) told me: "you don't have a computer?"... I told myself that I had to buy one and that was how I began using a computer... It changed my life. Otherwise, I would have lost touch with the association for example... They told me that's the way it works... They didn't send anything hand-written. [P11, female, 79 years]

In our association, some members wonder if it is absolutely necessary to train all the people to use a computer... most of us think that people have to know how to use a 
computer because there comes a time when people will be rejected if they don't know how to use it... there is no other way to do tax declarations, to buy tickets... the staff will tell you to buy tickets with an automatic dispenser. [P8, female, 75 years $]$

However, some participants considered it a social injustice that people have no choice but to use new technologies to get access to information and services.

It is a lack of choices... before, we had choices... now, we've no choices... I think it's an alienation of our liberty. [P4, female, 63 years]

There is a part of the population who exists and who has the right to exist... [P5, female, 81 years]

Social influence was considered a facilitator to technology use. Training was often provided by family and friends who helped older adults get familiarized with technology.

I have an I-phone 4. A lot of people help me use it. My grandson helps me use a part of it and my friend helps me use another part. I bought it myself. [P12, female, 70 years]

\section{Opinions on assistive ICTs}

Throughout FGs, we presented some assistive ICTs tailored to older adults, including a cognitive prosthesis (MEM-X: http://www.mem-X.com/), an assistive robot (Kompaï: $\underline{\text { http:// }}$ www.robosoft.com/robotic-solutions/healthcare/kompai/ kompai-rd.html), a companion robot (Paro: http://www. parorobots.com/), a simplified tablet PC (TOOTI-family: http://www.tootifamily.com/), and emergency response systems. Most of the participants reported that they did not need these kinds of products for the moment but some mentioned that there would be upcoming needs in the future when they became cognitively or physically frailer. For most of them, end users of assistive ICTs were very old people with major cognitive impairment or those who are lonely or isolated. As participants considered themselves as healthy and independent, they were not concerned by these kinds of products.

No, I don't think that I need it (cognitive prosthesis) now. My calendar is enough for me. I find it too expensive and I don't think that it provides more services than my agenda, which I look at all the time. So, I don't see any usefulness of this product that rings to remind me of an appointment... I'm still capable of looking up at my calendar. [P9, female, 83 years]

There are specific functionalities for the third age, the fourth age... and even the fifth age... when I go to a nursing home, this (simplified tablet PC) is what I'll have. [P14, female, 70 years]

If one day I need Paro, it will mean that I got really bad... it's pejorative to say this... but if really I needed it, it would means that I'm "out of order" or "doddering". [P13, female, 78 years]

\section{Discussion}

This study presents a project that informed older adults of the existence of different kinds of ICT-related products. We focused on the way participants perceived the project and how they reacted to ICTs presented throughout the sessions.

Results showed that this project was appreciated by participants because it offered a unique occasion for those who are curious about societal progress and wish to be upto-date and discover a variety of ICTs. In addition, the FGs allowed participants to express their concerns about aging issues and to anticipate problems and difficulties that they could encounter one day with aging. Participating to FGs also allowed participants to maintain an active engagement in life through involvement in social and productive activities and interaction with others, essentially for "successful aging". ${ }^{16}$

Results also showed that participants in general perceived the existence of a "digital divide" between the older and the younger generations, for whom ICT use is mainly mediated by institutional contexts (school and workplace). ${ }^{17}$ The generation effect, leading to less use of technology by older adults, was well documented in the literature..$^{2,11,18-20}$ Younger people are exposed to computers and the Internet earlier and earlier and most of them acquire skills during their childhood. In contrast, older people are only exposed to these new technologies late in their lives and have to learn new skills to use them. Apart from the skills issue, people of older generations might have more concerns about modifications in lifestyle, and in the society due to overreliance on technology. Therefore, concerns such as security, privacy issues, and diminution of human contact are often raised. ${ }^{11,21-23}$ Our findings also corroborated previous ones suggesting that older adults' uneasiness with ICTs might be due to disturbing awareness or fear that ICTs may be changing fundamental human nature or threatening the nature of what it means to care. ${ }^{24,25}$

Other than "generation" or "cohort" effects, cognitive, physical, attitudinal, and socioeconomic factors that affect adoption or acceptance of a variety of technologies are identified. Age-related sensorial, physical, and cognitive declines leading to difficulties in acquiring new skills in 
technology use are often reported as a barrier. ${ }^{21,23,26,27} \mathrm{With}$ regard to attitudinal barriers, older age is often found to be related to lower levels of interest, control, confidence, comfort, self-efficacy, and higher levels of technology anxiety. ${ }^{28-30}$ In addition, a lack of perceived need and usefulness toward technology is often identified as a reason

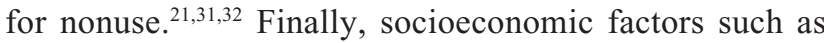
the cost of a product and the socioeconomic status of an older adult are often reported to be related to technology use or adoption. ${ }^{27}$

The impact of the digital divide is that older adults would be more disadvantaged and more disenfranchised compared to their younger counterparts. ${ }^{7}$ A digital divide is commonly considered as social inequality and social injustice that a society must find ways to bridge. On the other hand, social injustice might come from the fact that people are compelled to use technology to get access to information and services and to be a member of the society, as voiced by some of our participants who are not digitally included. However, not to be excluded from the society is one of the main reasons why older adults start using technology. It remains an important issue that older adults get appropriate training and support in ICT use. Classically, older adults get training and support from friends, family, and classes. Recently, it was suggested that ICT training through peer tutors is also effective. ${ }^{33}$ This training model is considered to be appropriate because it highlights the role of trainers as caring and sensitive people, capable of bringing adequate support for older adults. It was reported that adequate training has a positive impact not only on older adults' skill in technology use but also on their attitudes toward technology (less anxiety, more perceived usefulness, increased interest, and self-efficacy). ${ }^{33-36}$

Concerning older adults' attitudes toward ICT products tailored and marketed for them (the so-called gerontechnologies), although they are considered as useful, few participants considered themselves in need of these products. Their image of the end users of these kinds of technologies was very old people with considerable cognitive or physical impairment or those suffering from loneliness or social isolation. In the design literature, it is reported that some accommodations of a product, provided by accessible and adaptable design, are helpful to older adults. However, the fact that these features are noticeable may suggest to some older adults that they belong to a special group (very old, lonely/isolated, and disabled). ${ }^{37-39}$ Although a digital assistive device could compensate for cognitive or physical impairment, its acceptance is strongly hindered by one's desire to maintain an ideal self-image ${ }^{40}$ Some researchers argue that the "stigma" embodied by assistive ICT or "gerontechnology" device might constitute an important barrier to its acceptance. ${ }^{25,41-43}$

\section{Limitations of the study}

This exploratory qualitative research is not intended for generalization. A limitation of the present study may be its lack of representativeness in the sample and generalizability to a broader population. The participants of the study are mostly older adults who demonstrate "successful aging". They are globally healthy and independent, enjoy interactions with others, and maintain active engagement in life. Their opinions might not be representative. Frailer older adults with cognitive or physical impairment might have different opinions and attitudes toward ICT-related products. For example, a Dutch national survey on the determiners of the adoption of home telecare shows that among clients with a connection to home telecare, those who are older and chronically ill, already receiving long-term care, and living alone might perceive more benefit from the home telecare system and be more inclined to adopt it. ${ }^{44}$ It might be that in frailer older adults, the need to compensate for their impairment would outweigh the need to maintain a certain desired self-image. Future studies could investigate this issue by using a qualitative approach to compare a group of healthy older adults to a group of frail older adults.

\section{Conclusion}

This study presented a 2-year project, during which FGs were organized with demonstrations of ICT-related products to older adults. Participants' appreciation for the project was presented and we have identified overarching themes on participants' appreciation of the project and their opinions and attitudes about ICT-related products. Results indicated that participants rated this project positively. They generally perceived a digital divide between the older and the younger generations, yet they began adopting different kinds of ICTs in order to fit in with the society. With regard to ICT-related ATs, they manifested a lack of perceived need and usefulness. The so-called gerontechnologies targeted specifically to older adults contain stigmatizing symbolism that might prevent them from adopting them.

\section{Acknowledgments}

This project was supported by the "Fondation de France" through the 2011 program "Droit au choix et droit au risque des personnes âgées. Former et agir". We also thank Fanny Lorentz and Véronique Ferracci for their help in the management of the project. 


\section{Disclosure}

The authors report no conflicts of interest in this work.

\section{References}

1. Harrington TL, Harrington MK. Gerontechnology: Why and How. Maastricht, The Netherlands: Shaker; 2000.

2. Bouma H, Fozard JL, Bouwhuis DG, Taipale V. Gerontechnology in perspective. Gerontechnology. 2007;6(4):190-216.

3. Gaßner KS, Conrad M. ICT Enabled Independent Living for the Elderly: A Status-quo Analysis on Products and the Research Landscape in the Field of Ambient Assisted Living (AAL) in EU-27. Germany: IIT; 2010: 3897501600.

4. Pressler KA, Ferraro KF. Assistive device use as a dynamic acquisition process in later life. Gerontologist. 2010;50(3):371-381.

5. McCreadie C, Tinker A. The acceptability of assistive technology to older people. Ageing Soc. 2005;25(1):91-110.

6. Olson KE, O'Brien MA, Rogers WA, Charness N. Diffusion of technology: frequency of use for younger and older adults. Ageing Int. 2011; 36(1):123-145.

7. Czaja SJ, Charness N, Fisk AD, et al. Factors predicting the use of technology: findings from the Center for Research and Education on Aging and Technology Enhancement (CREATE). Psychol Aging. 2006;21(2):333.

8. Gombault V. L'internet de plus en plus prisé, l'internaute de plus en plus mobile: Conditions de vie des ménages. Paris: Insee; 2013.

9. Wu Y-H, Cristancho-Lacroix V, Fassert C, Faucounau V, de Rotrou J, Rigaud A-S. The attitudes and perceptions of older adults with mild cognitive impairment toward an assistive robot. J Appl Gerontol. In press 2014.

10. Rogers EM. Diffusion of Innovations. Glencoe: Free Press; 1962.

11. Heinz M, Martin P, Margrett JA, et al. Perceptions of technology among older adults. $J$ Gerontol Nurs. 2013;39(1):42-51.

12. Kramer B. Dementia caregivers in Germany and their acceptance of new technologies for care: the information gap. Public Policy Aging Rep. 2014;24(1):32-34.

13. Crabtree BF, Miller WL. Research practice settings: a case study approach. In: Crabtree BF, Miller WL, editors. Doing Qualitative Research. Thousand Oaks, CA: Sage; 1999:71-88.

14. Braun V, Clarke V. Using thematic analysis in psychology. Qual Res Psychol. 2006;3:77-101.

15. Guba EG, Lincoln Y. Fourth Generation Evaluation. California: Sage; 1989.

16. Rowe JW, Kahn RL. Successful aging. Gerontologist. 1997;37(4): 433-440.

17. Neice DC. Measures of Participation in the Digital Technostructure: Internet Access. Brighton: University of Sussex, SPRU; 1998.

18. Docampo Rama M, Ridder Hd, Bouma H. Technology generation and age in using layered user interfaces. Gerontechnology. 2001;1(1): 25-40.

19. Mahmood A, Yamamoto T, Lee M, Steggell C. Perceptions and use of gerotechnology: implications for aging in place. J Housing Elderly. 2008;22(1-2):104-126.

20. Melenhorst AS, Rogers WA, Bouwhuis DG. Older adults' motivated choice for technological innovation: evidence for benefit-driven selectivity. Psychol Aging. 2006;21(1):190-195.

21. Chen K, Chan AH-S. Use or non-use of gerontechnology - a qualitative study. Int J Environ Res Public Health. 2013;10(10):4645-4666.

22. Boise L, Wild K, Mattek N, Ruhl M, Dodge HH, Kaye J. Willingness of older adults to share data and privacy concerns after exposure to unobtrusive in-home monitoring. Gerontechnology. 2013;11(3):428-435.
23. Parker SJ, Jessel S, Richardson JE, Reid MC. Older adults are mobile too! Identifying the barriers and facilitators to older adults' use of mHealth for pain management. BMC Geriatr. 2013;13:43.

24. McLean A. Ethical frontiers of ICT and older users: cultural, pragmatic and ethical issues. Ethics Inf Technol. 2011;13(4):313-326.

25. Wu Y-H, Wrobel J, Cornuet M, Kerhervé H, Damnée S, Rigaud A-S. Acceptance of an assistive robot in older adults: a mixed-method study of human - robot interaction over a 1-month period in the Living Lab setting. Clin Interv Aging. 2014;9:801-811.

26. Charness N, Boot WR. Aging and information technology use potential and barriers. Curr Dir Psychol Sci. 2009;18(5):253-258.

27. Elliot AJ, Mooney CJ, Douthit KZ, Lynch MF. Predictors of older adults' technology use and its relationship to depressive symptoms and well-being. J Gerontol B Psychol Sci Soc Sci. 2013;69(5):667-677.

28. Sharit J, Czaja SJ, Nair S, Lee CC. Effects of age, speech rate, and environmental support in using telephone voice menu systems. Hum Factors. 2003;45(2):234-251.

29. Jung Y, Peng W, Moran M, et al. Low-income minority seniors' enrollment in a cybercafé: psychological barriers to crossing the digital divide. Educ Gerontol. 2010;36(3):193-212.

30. Ellis RD, Allaire JC. Modeling computer interest in older adults: the role of age, education, computer knowledge, and computer anxiety. Hum Factors. 1999;41(3):345-355.

31. Selwyn N, Gorard S, Furlong J, Madden L. Older adults' use of information and communications technology in everyday life. Ageing Soc. 2003;23(5):561-582.

32. Heart $\mathrm{T}$, Kalderon E. Older adults: are they ready to adopt health-related ICT? Int J Med Inf. 2011;82(11):e209-e231.

33. Woodward AT, Freddolino PP, Wishart DJ, et al. Outcomes from a peer tutor model for teaching technology to older adults. Ageing Soc. 2013;33(8):1315-1338.

34. Xie B, Bugg JM. Public library computer training for older adults to access high-quality Internet health information. Libr Inform Sci Res. 2009;31(3):155-162.

35. Lagana L, Oliver T, Ainsworth A, Edwards M. Enhancing computer self-efficacy and attitudes in multi-ethnic older adults: a randomised controlled study. Ageing Soc. 2011;31(6):911-933.

36. Irizarry C, Downing A, West D. Promoting modern technology and internet access for under-represented older populations. J Technol Hum Serv. 2002;19(4):13-30.

37. Story MF. Maximizing usability: the principles of universal design. Assist Technol. 1998;10(1):4-12.

38. Deardorff CJ, Birdsong C. Universal design: clarifying a common vocabulary. Housing Soc. 2003;30(2):119-138.

39. Audirac I. Accessing transit as universal design. J Plann Lit. 2008; 23(1):4-16.

40. Karlsson E, Axelsson K, Zingmark K, Sävenstedt S. The challenge of coming to terms with the use of a new digital assistive device: a case study of two persons with mild dementia. Open Nurs J. 2011; 5:102-110.

41. Blackman T. Care robots for the supermarket shelf: a product gap in assistive technologies. Ageing Soc. 2013;1(1):1-19.

42. Gucher C. Technologies du «Bien vieillir et du lien social»: questions d'acceptabilité, enjeux de sens et de questions d'acceptabilité, enjeux de sens et de continuité de l'existence-la canne et le brise-vitre. Gérontologie et Société. 2012;141:27-39.

43. Parette P, Scherer M. Assistive technology use and stigma. Educ Train Dev Disab. 2004;39(3):217-226.

44. Peeters JM, de Veer AJ, van der Hoek L, Francke AL. Factors influencing the adoption of home telecare by elderly or chronically ill people: a national survey. J Clin Nurs. 2012;21:3183-3193. 
Clinical Interventions in Aging

\section{Publish your work in this journal}

Clinical Interventions in Aging is an international, peer-reviewed journal focusing on evidence-based reports on the value or lack thereof of treatments intended to prevent or delay the onset of maladaptive correlates of aging in human beings. This journal is indexed on PubMed Central, MedLine,

CAS, Scopus and the Elsevier Bibliographic databases. The manuscript management system is completely online and includes a very quick and fair peer-review system, which is all easy to use. Visit http://www.dovepress. $\mathrm{com} /$ testimonials.php to read real quotes from published authors.

Submit your manuscript here: http://www.dovepress.com/clinical-interventions-in-aging-journal 